\title{
Abiogenesis in Upper Secondary Biology Curricula
}

\author{
Barend Vlaardingerbroek
}

Published online: 11 March 2010

(C) Springer Science+Business Media, LLC 2010

\begin{abstract}
Biological evolution and abiogenesis are distinct branches of science, although they are closely related in the context of a holistic evolutionary conceptual framework. The relationship between evolution and abiogenesis furnishes profound insights into the nature of science, a much emphasised aspect of modern science education. But there appears to be a great deal of ambiguity about the place of abiogenesis in upper secondary curricula, being the stage of formal education at which students are usually first exposed to evolutionary theory in any depth. Some official curricula completely omit any reference to the issue, others fleetingly touch on it, and yet others fully incorporate it. This paper argues that abiogenesis should be included in upper secondary biology curricula, but that students need to be made aware of the distinctions between chemical and biological evolutionary theories.
\end{abstract}

Keywords Evolution · Abiogenesis · Chemical evolution . Biology curriculum

\section{Introduction}

The phrase "the theory of evolution" in common parlance has a somewhat nebulous meaning (National Center for Science Education, n.d.). It is often applied to the entire secular mindset concerning the origin and development of the cosmos, including life - an angle strongly reinforced by much anti-evolution propaganda. But in the context of biology, biological evolution and the origin of life-

B. Vlaardingerbroek $(\bowtie)$

American University of Beirut,

Beirut, Lebanon

e-mail: bv00@aub.edu.lb abiogenesis-represent distinct theoretical frameworks which have developed quite separately over the past century and a half since the publication of Darwin's The Origin of Species.

School students are usually first exposed to a systematic study of evolution in the upper secondary years. A function of modern science education is to instill in students an awareness of the nature of science, including its history and philosophy, and connections among disciplines both within and outside science (Mathews 1994). Within this framework, it is of critical importance that students are cognizant of the scope of scientific theories so that they can comprehend the linkages between them and other conceptual frameworks. The delineation of the evolutionary paradigm as taught in biology classes thereby assumes a crucial epistemological function.

This paper commences with a historical overview of abiogenesis as an addendum to evolution. It then presents a brief survey of upper secondary biology curricular statements from twelve education systems hailing from nine countries to see how they deal with the issue of the origin of life within the context of evolution.

\section{Abiogenesis as a Codicil to Evolution}

Charles Darwin's case as put in 1859 took as its starting point the existence of "a few forms or ... one [into which life had been] originally breathed" (last sentence of The Origin; the words "by the Creator" were added in subsequent editions [Kuschera 2009]). This position was largely a reflection of deism - the notion, influential in England from the late 17th century until the early 1800s, that God had created the "laws" which ran the universe, but having done so did not intervene any further in the 
workings thereof. Darwin's grandfather Erasmus had been a prominent deist, while Charles Lyell, the founder of modern geology and Darwin's mentor at Cambridge, was probably the most influential deist in the scientific community of his time. It was little wonder, therefore, that the young Charles had found himself gravitating towards deism while at university (Ruse 1998); he was probably no longer of this mind by 1859 but considered it prudent to not exclude the theistic angle (Farley 1972; Kuschera 2009). He never commented publicly on the issue of the origin of life, although he did outline in almost whimsical terms a "chemical soup" scenario in a letter to Hooker (Bada and Lazcano 2009).

That living organisms originated from inanimate material was not a new idea; "spontaneous generation" had been debated since antiquity, and remained a hot topic in Victorian science even after Pasteur (for a full account see Strick 2002), albeit applied mainly to microbes (cf. "formulae" for "making" vermin that were in currency during preceding centuries). While vigorous, the spontaneous generation debate had not been particularly divisive in terms of fundamental beliefs concerning origins; in the absence of blood ties between groups of different organisms, it was of no great consequence whether a mouse or a woodlouse could appear from inanimate matter or not. But the entry of evolutionary lineages, particularly the phylogeny of Ernst Haeckel's Generelle Morphologie of 1866 and beyond which showed micro-organisms as being at the base of the tree of common descent, gave spontaneous generation a new meaning. Thomas Huxley coined the term 'abiogenesis' to distance the issue from the historical baggage of spontaneous generation.

Paradoxically, Haeckel was at first of the opinion that abiogenesis was an on-going process on the seabed, leading to the "discovery" of a "micro-organism" that Huxley named Bathybius haeckelii but which turned out to be an artifact of alcohol preservation of marine sedimentary samples (Rehbock 1975). The Bathybius farce was historically significant in that it relegated abiogenesis to a discrete point in the remote past (Huxley 1870; RaulinCerceau 2004). In so doing, it placed abiogenesis at the interface of non-life and life as a prerequisite for evolution; in Strick's (2002, p.79) words, abiogenesis had become a "necessary correlate to evolution". But ironically, the early English Darwinists balked at the idea of evolutionary theory embracing abiogenesis because of its speculative nature (Farley 1972; Strick 1999). Other than the work of Oparin and Haldane in the 1920s, abiogenesis as a focus of scientific endeavour maintained a low profile until the middle of the twentieth century when the experimental work of Urey and Miller - the synthesis of amino-acids from the gases thought to have constituted the early Earth's atmosphere - brought it back to the fore.
The introduction of the term "chemical evolution" has blurred the distinction between biological evolution and abiogenesis, but the two remain fundamentally different theories. As summarized by the National Center for Science Education (n.d.):

Evolution is a scientific theory that explains the emergence of new varieties of living things in the past and in the present; it is not a 'theory of origins' about how life began.

Abiogenetic models have come a long way since early musings about simple organic substances being produced in primordial ponds, but nonetheless remain focused on the prebiotic level (Fleischaker 1990). Equating abiogenesis with evolutionary theory is listed as a misconception by the University of California's Berkeley 'Understanding Evolution' internet resource, although it is noted that "Science does try to investigate how life started... but [this is] not the central focus of evolutionary theory" (University of California, n.d.). With the mounting interest in finding life outside our own planet, abiogenesis has increasingly become an adjunct of modern astronomy (Carrapiço et al. 2002).

\section{Evolution and Abiogenesis in Upper Secondary Biology Curricula}

Should abiogenesis be taught in upper secondary biology? It seems a practical impossibility to bypass the topic; students will inevitably press their teachers about the origin of life as such, and class time will be spent on it whether abiogenesis is in the syllabus or not. The writer of this paper would accordingly reply to the question in the affirmative, albeit with the caveat that a clear distinction be made between chemical and biological evolution as distinct branches of science.

In order to gain a broad insight into the treatment of abiogenesis in upper secondary biology education, twelve upper secondary biology curricular statements were procured from nine anglophone countries: England (Assessment and Qualifications Authority 2006 and 2009); USA (New York [University of the State of New York 2009] and California [California Department of Education 1998]); Canada (Alberta [Alberta Education 2007] and Quebec [Quebec Ministry of Education 1990]), Australia (New South Wales [Board of Studies New South Wales 2009] and Queensland [Queensland Studies Authority 2006]), India (Central Board of Secondary Education 2008); Malaysia (Malaysian Examination Council 2003); South Africa (South Africa Department of Education 2003); New Zealand (New Zealand Ministry of Education 2007); and Singapore (Singapore Assessment and Examinations Board 2009a and 
2009b). Curriculum writing styles vary considerably; some are intensely content-prescriptive while others focus more on skills. The comparison of two official curricular documents may not always be comparing like with like. Curricular prescriptions are, moreover, only one factor in deciding what happens in classrooms. Other factors include the textbooks and other source materials used, whether there is an external examination to prepare students for, and teachers' personal stances on the topic being taught - probably a major factor in the context of evolution. There is no insinuation on the part of the writer of this paper that the curricula cited are necessarily reliable guides to what happens in biology classrooms. The aim of this aspect of the study was merely to note the absence or presence of abiogenesis in official curricular statements, and its apparent relationship to evolution in the event of the latter.

All curricula contain material on evolution, but six contain no allusion to the origin of life: England, Alberta, Malaysia, South Africa, New Zealand and Singapore. The California curriculum notes that life has been on Earth for three billion years, but does not elaborate on that theme. In the New York curriculum, it is noted that "Billions of years ago, life on Earth is thought by many scientists to have begun as simple, single-celled organisms" (University of the State of New York 2009, p. 12); abiogenesis is hinted at, but again is not developed as a curricular theme.

The remaining curricula engage abiogenesis to varying degrees. The brief Indian curricular evolution prescription begins with "the origin of life, theories and evidence" and moves on to mechanisms of biological evolution (Central Board of Secondary Education 2008, p. 97). The Queensland curriculum notes that "life originated in water" and states that "All of the inorganic and organic compounds necessary for self-replication and membrane assembly could have formed spontaneously under conditions that existed on early earth" (Queensland Studies Authority 2006). Abiogenesis (referred to as "biochemical evolution") [Quebec Ministry of Education 1990, p. 24] and the evolution of the first cells is thoroughly treated in a separate unit from biological evolution by the Quebec curriculum. The New South Wales curriculum explicitly applies the evolutionary paradigm to chemical and cellular evolution through to the evolution of multicellular organisms (Board of Studies New South Wales 2009). The Urey-Miller experiments are included alongside studies of stromatolites. In summary, the curricular status of abiogenesis ranges from invisibility to a fullyfledged aspect of evolutionary theory within a unified chemical/biological evolutionary conceptual framework. At the very least, it may be said that these observations are indicative of a high degree of ambiguity concerning the scope of the evolution concept as it is taught at secondary school level.

\section{Concluding Remarks}

The past century and a half has witnessed the emergence of a holistic evolutionary mindset which encompasses cosmological, geological, chemical and biological evolution. This has created a semantic problem with regard to the use of the word "evolution." It is not in itself a new problem, as scientific discourse often attributes narrow meanings to words which may be more broadly applied in common usage, and teachers need to clearly distinguish between scientific theories of biological and chemical evolution, and the paradigm of evolution as an overarching conceptual framework. Given the current emphasis in science education on epistemological aspects of science, students should not be left regarding biological evolution and abiogenesis as aspects of the same scientific theory-an impression likely to be made by both cursory references to the origin of life in the context of a teaching unit on biological evolution and by approaches which present abiogenesis as part and parcel of a unified evolutionary theory. Abiogenesis needs to be written into upper secondary biology curricula, but as a topic separate from, albeit related to, biological evolution.

\section{References}

Alberta Education. Biology 20-30. Edmonton: Alberta Education; 2007.

Assessment and Qualifications Alliance. GCE AS and A level subject criteria for science. London: Assessment and Qualifications Alliance; 2006.

Assessment and Qualifications Alliance. GCE AS and A level specification-Biology. London: Assessment and Qualifications Alliance; 2009.

Bada JL, Lazcano A. The origin of life. In: Ruse M, Travis J, editors. Evolution-The first four billion years. New York: Harvard University Press; 2009.

Board of Studies New South Wales. Biology stage 6 syllabus. Sydney: Board of Studies New South Wales; 2009.

California Department of Education. Science content standards. Sacramento: California Department of Education; 1998.

Carrapiço F, Lourenço A, Fernandes L, Rodrigues T. A journey to the origins: the astrobiology paradigm in education. Proceedings of SPIE. 2002;4495:295-300.

Central Board of Secondary Education. Senior school curriculum, vol. 1. New Delhi: Central Board of Secondary Education; 2008.

Farley J. The spontaneous generation controversy (1859-1880): British and German reactions to the problem of abiogenesis. J Hist Biol. 1972;5(2):285-319.

Fleischaker G. Origins of life: an operational definition. Orig Life Evol Biosph. 1990;20:127-37.

Huxley TH. Biogenesis and abiogenesis. Collected Essays, vol. 8. New York: D. Appleton; 1870. p. 229-71.

Kuschera U. Darwin's philosophical imperative and the furor theologicus. Evolution: Education and Outreach; 2009. doi:10.1007/s12052-009-0166-8.

Malaysian Examination Council. Malaysia higher school certificate biology syllabus. 2nd ed. Kuala Lumpur: Malaysian Examination Council; 2003. 
Mathews MR. Science teaching-The role of history and philosophy of science. New York: Routledge; 1994.

National Center for Science Education. (n.d.). Retrieved on 6 January 2010 from http://ncse.com.

New Zealand Ministry of Education. The New Zealand curriculum. Wellington: New Zealand Ministry of Education; 2007.

Quebec Ministry of Education. General biology 535-534. Montreal: Quebec Ministry of Education; 1990.

Queensland Studies Authority. Senior syllabus-Biology. Brisbane: Queensland Studies Authority; 2006.

Raulin-Cerceau F. Analysis of the works of the German naturalist Ernst Haeckel (1834-1919) on the origin of life. In: Seckbach J, Cheta-Flores J, Owen T, Raulin F, editors. Life in the universeFrom the Miller experiment to the search for life in other worlds. Dordrecht: Kluwer; 2004. p. 349-52.

Rehbock PF. Huxley, Haeckel, and the oceanographers: the case of Bathybius haeckelii. Isis. 1975;66(4):504-33.

Ruse M. Darwinism and atheism: different sides of the same coin? Endeavour. 1998;22(1):17-9.
Singapore Examinations and Assessment Board. Biology higher 1 (syllabus 8875). Singapore: Singapore Examinations and Assessment Board; 2009a.

Singapore Examinations and Assessment Board. Biology higher 2 (syllabus 9747). Singapore: Singapore Examinations and Assessment Board; 2009b.

South Africa Department of Education. National curriculum statement grades 10-12 (general) - Life sciences. Pretoria: South Africa Department of Education; 2003.

Strick J. Darwinism and the origin of life: the role of H.C. Bastian in the British spontaneous generation debates, 1969-1873. J Hist Biol. 1999;32:51-92.

Strick JE. Sparks of life-Darwinism and the Victorian debates over spontaneous generation. Cambridge: Harvard University Press; 2002.

University of California. (n.d.) Misconception: 'Evolution is a theory about the origin of life'. Retrieved on 6 January 2010 from http:// evolution.berkeley.edu/evosite/misconceps/IAorigintheory.shtml.

University of the State of New York. The living environment core curriculum. New York: State Education Department; 2009. 